\title{
Cost-effectiveness of rotavirus vaccination in Bolivia from the state perspective
}

\section{Citation}

Smith, Emily R., Emily E. Rowlinson, Volga Iniguez, Kizee A. Etienne, Rosario Rivera, Nataniel Mamani, Rick Rheingans, Maritza Patzi, Percy Halkyer, and Juan S. Leon. 2011. "CostEffectiveness of Rotavirus Vaccination in Bolivia from the State Perspective." Vaccine 29 (38) (September): 6704-6711. doi:10.1016/j.vaccine.2011.05.038.

\section{Published Version}

doi:10.1016/j.vaccine.2011.05.038

\section{Permanent link}

http://nrs.harvard.edu/urn-3:HUL.InstRepos:22975301

\section{Terms of Use}

This article was downloaded from Harvard University's DASH repository, and is made available under the terms and conditions applicable to Other Posted Material, as set forth at http:// nrs.harvard.edu/urn-3:HUL.InstRepos:dash.current.terms-of-use\#LAA

\section{Share Your Story}

The Harvard community has made this article openly available.

Please share how this access benefits you. Submit a story.

\section{Accessibility}




\title{
Cost-Effectiveness of Rotavirus Vaccination in Bolivia from the State Perspective
}

\author{
Emily R. Smith ${ }^{1, \dagger}$, Emily E. Rowlinson ${ }^{1, \dagger}$, Volga Iniguez $^{2}$, Kizee A. Etienne ${ }^{1}$, Rosario \\ Rivera $^{2}$, Nataniel Mamani ${ }^{2}$, Rick Rheingans ${ }^{3}$, Maritza Patzi ${ }^{4,6}$, Percy Halkyer $^{5,6}$, and Juan S. \\ Leon ${ }^{1, *}$ \\ ${ }^{1}$ Hubert Department of Global Health, Rollins School of Public Health, Emory University, Atlanta, \\ GA \\ 2 Instituto de Biología Molecular y Biotecnología, Universidad Mayor de San Andrés, La Paz, \\ Bolivia \\ ${ }^{3}$ Department of Environmental and Global Health, Center for African Studies, University of \\ Florida, Gainesville, FL \\ ${ }^{4}$ Ministerio de Salud y Deportes de Bolivia \\ 5 PanAmerican Health Organization \\ ${ }^{6}$ Programa Ampliado de Inmunización
}

\begin{abstract}
BACKGROUND-In Bolivia, in 2008, the under-five mortality rate is 54 per 1000 live births. Diarrhea causes $15 \%$ of these deaths, and $40 \%$ of pediatric diarrhea-related hospitalizations are caused by rotavirus illness (RI). Rotavirus vaccination (RV), subsidized by international donors, is expected to reduce morbidity, mortality, and economic burden to the Bolivian state. Estimates of illness and economic burden of RI and their reduction by RV are essential to the Bolivian state's policies on RV program financing. The goal of this report is to estimate the economic burden of $\mathrm{RI}$ and the cost-effectiveness of the RV program.
\end{abstract}

METHODS-To assess treatment costs incurred by the healthcare system, we abstracted medical records from 287 inpatients and 6,751 outpatients with acute diarrhea between 2005 and 2006 at 5 sentinel hospitals in 4 geographic regions. RI prevalence rates were estimated from 4 years of national hospital surveillance. We used a decision-analytic model to assess the potential costeffectiveness of universal RV in Bolivia.

RESULTS-Our model estimates that, in a 5-year birth cohort, Bolivia will incur over US\$3 million in direct medical costs due to RI. RV reduces, by at least $60 \%$, outpatient visits, hospitalizations, deaths, and total direct medical costs associated with rotavirus diarrhea. Further, $\mathrm{RV}$ was cost-savings below a price of US $\$ 3.81$ per dose and cost-effective below a price of US $\$ 194.10$ per dose. Diarrheal mortality and hospitalization inputs were the most important drivers of rotavirus vaccine cost-effectiveness.

(C) 2011 Elsevier Ltd. All rights reserved.

*Author for correspondence. Phone: (404) 727-7443, Fax: (404) 727- 4590, juan.leon@emory.edu.

${ }^{\dagger}$ Both authors contributed equally to this work

Publisher's Disclaimer: This is a PDF file of an unedited manuscript that has been accepted for publication. As a service to our customers we are providing this early version of the manuscript. The manuscript will undergo copyediting, typesetting, and review of the resulting proof before it is published in its final citable form. Please note that during the production process errors may be discovered which could affect the content, and all legal disclaimers that apply to the journal pertain. 
DISCUSSION-Our data will guide Bolivia's funding allocation for RV as international subsidies change.

\section{INTRODUCTION}

Rotavirus is the leading cause of severe gastroenteritis among children under five years of age and is globally responsible for an estimated 111 million episodes of diarrhea requiring home care, 25 million clinic visits, 2 million hospitalizations, and as many as 592,000 deaths annually $[1,2]$. Children in low-income countries are disproportionately affected by rotavirus, accounting for more than $80 \%$ of these deaths $[1,2]$. The introduction of effective rotavirus vaccines is a promising intervention in preventing global diarrheal morbidity and mortality. However, the high cost of the new rotavirus vaccines, compared to relative costs of pennies per dose for older vaccines, has resulted in limited implementation in low-income countries.

Estimates of the economic burden of rotavirus diarrhea vary substantially by country [3-30]. For example, adjusting by population, the annual per capita costs for treatment of rotavirus diarrhea ranged from US $\$ 0.07$ per person in the Dominican Republic [7] to over US\$0.97 per person in the United States [13]. Therefore, country-specific rotavirus cost-burden estimates are essential to assess the country-specific cost effectiveness of the rotavirus vaccine. Cost-effectiveness analysis (CEA) outcome measures permit standardized comparisons of cost-effectiveness across a range of health interventions. The results of published CEAs for rotavirus vaccination have varied. Out of 36 published studies, universal rotavirus vaccination was determined to be potentially cost saving in three studies [31-33], potentially cost-effective in 27 studies $[3,4,6,13,29,30,32,34-52]$, unlikely to be costeffective in six studies [53-58], and inconclusive in one study [59]. Estimates of costs per DALY averted ranged from US\$15.32 in middle-income Asian countries (vaccine price of US $\$ 2$ per course) [6] to US $\$ 10,656$ in Chile (vaccine price of US $\$ 24$ per course) [7]. The break-even price of the vaccine, defined as the price at which vaccination costs equal the costs saved by the health system, ranged from US\$0.18 in low-income Asian countries [6] to US\$54 USD in Taiwan [57].

While many Latin American countries have undertaken cost-effectiveness analyses to facilitate policy decisions regarding rotavirus vaccination, Bolivia remains an exception. Bolivia is one of the least developed countries in the Americas, with nearly $60 \%$ of the population living in conditions of poverty and nearly $25 \%$ living in conditions of extreme poverty [60]. The nation suffers from the region's highest rates of childhood mortality, and the World Health Organization (WHO) estimates that diarrhea is responsible for 15\% of these deaths [61]. In 2008, Bolivia implemented a universal rotavirus vaccination campaign with financial support from The Global Alliance for Vaccines and Immunization (GAVI) through the year 2017. The goal of this paper is to fill gaps in knowledge regarding the economic burden of rotavirus and cost-effectiveness of the rotavirus vaccination program in Bolivia. The subsequent analysis provides data for decision makers regarding the projected economic impact of vaccination at a range of vaccine prices reflecting the dynamic market value of this vaccine.

\section{METHODS}

Model

To calculate the cost-effectiveness of universal rotavirus vaccination in Bolivia, data were analyzed through an economic model developed by Rheingans et al. [44, 51]. This decision model was created using Microsoft 2000 Excel software (Microsoft Corporation, Redmond, Washington) and compares the cost of universal rotavirus vaccination in Bolivia 
(intervention costs) with the hypothetical treatment costs of rotavirus diarrhea potentially prevented by vaccination. Model inputs included country-specific economic, health systems, demographic and rotavirus epidemiology data, encompassing rotavirus disease morbidity and mortality, healthcare utilization and costs for rotavirus-associated events, and vaccination coverage (Table 1). The model examined cost-effectiveness from a health system point-of-view, and no data regarding societal costs borne by individuals (e.g. costs to fill prescriptions, work days lost, etc.) were included.

\section{Rotavirus Morbidity and Mortality}

Diarrheal mortality in children under 5 years of age and an estimate of annual diarrheal deaths in Bolivia was calculated using 2010 mortality rates from the World Health Organization (WHO) [62]. We assumed the proportion of diarrhea deaths due to rotavirus was the same as the proportion of hospitalized cases due to rotavirus, as etiological data was not available for diarrhea mortality. We estimated the five-year cumulative risk for hospitalization and outpatient care due to rotavirus disease based on administrative data from the National Statistics Institute of Bolivia [63], the 2003 birth cohort (251,000 consistent through 2009) [64], and data on the proportion of these events due to rotavirus, as identified by the National Rotavirus Surveillance Program (NRSP) in Bolivia (Table 1).

The rates of hospitalization and outpatient care for diarrheal diseases were calculated by dividing the annual number of hospitalizations and outpatient visits due to diarrhea (National Statistics Institute in Bolivia [65]) by the birth cohort $(251,000)$ [64]. The proportion of hospitalized children with rotavirus diarrhea was obtained from data from Bolivia's National Rotavirus Surveillance Network. Within surveillance hospitals, rotavirus diarrhea was defined as a child whose inpatient stool tested positive for rotavirus with the OXOID ProSpecT ${ }^{\mathrm{TM}}$ Rotavirus EIA Kit test (Oxoid, United Kingdom). The average length of stay for children treated for rotavirus in each type of facility was calculated from patient data collected as part of this study. A summary of the baseline inputs for the model is in Table 1.

\section{Study Population}

Data collection on treatment costs took place at five sentinel hospitals (Hospital Boliviano Holandes in El Alto, Hospital Materno Infantil and Hospital del Nino in La Paz, Centro Pediatria Albino R. Patiño in Cochabamba, and Hospital Mario Ortiz Suarez in Santa Cruz) participating in Bolivia's rotavirus surveillance program. These sites included both privately and publicly funded hospitals, and pediatric and general hospitals. Data was abstracted from inpatient and emergency department records of children less than 60 months of age treated for acute diarrheal disease.

The inpatient study population included a total of 287 patients admitted to the hospital for at least one night with diarrheal disease between August $1^{\text {st }}, 2005$ and August $30^{\text {th }}, 2006$. WHO guidelines for selecting an appropriate sample size suggest selection of every fifth patient with a diagnosis of acute diarrhea [66], however, we selected every third inpatient to ensure an adequate sample size. The outpatient study population included all 6,751 patients who presented to the emergency departments of surveillance hospitals with acute diarrhea between January 1, 2006 and December 31, 2006. Outpatient records with missing data regarding treatment or diagnostics were removed from the database to avoid underestimation of direct medical costs. Exclusion criteria included age over 60 months, dysentery, or a note of suspected bacterial, parasitic, dietary or other non-viral cause of diarrhea. Patients with a co-morbidity of pneumonia were also excluded to avoid the inclusion of costs not related to diarrhea treatment. 


\section{Cost Data}

Cost data was estimated from medical records data and previously published estimates. Only direct medical costs were included in the calculations of cost data.

Inpatient Costs-We found a wide variation in hospital bed-day cost data both between hospitals and among patients at the same hospital based on insurance coverage. Despite protracted research and interviews with the hospitals accounting department and Ministry officials, we could not guarantee that hospital bed-day costs excluded government subsidies or used consistent pricing methodology. Therefore, for consistency across facilities and reliability of the price of a hospital bed-day to the state, we used WHO 2005 countryspecific estimates of unit-costs for these patient services [67]. All hospitals in the study fit the WHO's definition of a tertiary hospital [68]; therefore, tertiary-level cost estimates were used for all inpatients and outpatients who received care in a hospital setting. These estimates account for costs such as personnel, capital, and food, but exclude diagnostics and medications.

Medications, medical equipment, and diagnostic tests ordered for inpatients were abstracted from pharmacy records and patient charts. Drug and medical equipment costs were estimated from Management Sciences for Health's (MSH) International Drug Price Indicator Guide [69] or the International Dispensary Association's (IDA) catalogue [70]. If a medication was not listed in either of these sources, Bolivia's government health insurance reimbursement rate for the given medication was used. Diagnostic costs were not available from either MSH or IDA; therefore Bolivia's government health insurance reimbursement rate was used. Costs for which data was available in Bolivianos (BOB) were converted into USD using the 2008 exchange rate of 1 BOB equal to US\$0.125.

Bolivia's health care system follows a three-tiered standardized guide for treating diarrhea according to the severity of dehydration: Plan A for mild dehydration, Plan B for moderate dehydration, and Plan C for severe dehydration. Plans A and B can be administered orally over the course of several hours and Plan $\mathrm{C}$ is designed to be administered intravenously over 2 days of inpatient care. Three assumptions were made to estimate treatment and diagnostics costs: 1) if a specific Plan was indicated in patient records, all specified components of the Plan were used plus any additional recorded medicines or diagnostics. 2) If no Plan was indicated, but any individual components of intravenous rehydration were recorded, then it was assumed that 1 Plan C package was administered for every 2 days of inpatient treatment. 3) If no Plan or intravenous rehydration was indicated, but specific medications were indicated ( $5 \%$ of records), only those indicated medications were used to calculate cost of treatment.

Hospital Outpatient Costs: No outpatient visit cost estimates for treatment in a hospital emergency department were available from surveillance facilities; therefore WHO-CHOICE cost estimates for this type of visit were used. Medications, IV rehydration components, medical equipment, and diagnostics ordered for each patient were abstracted using the methods described above. If Plan $\mathrm{C}$ was indicated in the records, it was assumed that the cost for an entire Plan C package was incurred. This is due to the fact that a full Plan C package cannot be administered in one day; however, the package components cannot be administered for a second patient and must be discarded if a second day of treatment is not completed.

Outpatient Treatment in a non-Hospital Setting: Because we did not collect data from outpatient treatments of a diarrheal episode in non-hospital settings, we assumed that outpatient treatments in these settings was limited to Plan A. Therefore, we estimated the 
cost of treatment in this setting as the cost of a Plan A package plus the WHO-CHOICE estimate of an outpatient visit cost in a non-hospital setting [67].

\section{Vaccine Characteristics}

National coverage of Diphtheria, Pertussis and Tetanus (DPT) vaccine was used as a proxy for the potential coverage of rotavirus vaccination because the recommended schedule is the same for both vaccines. Data on DPT 1 and 2 vaccination coverage and timing was calculated from the 2003 Bolivia Demographic and Health Survey [71]. Vaccine efficacy was estimated to be $85 \%$ against both deaths and hospitalizations due to rotavirus [72]. Because children who are at higher risk for rotavirus mortality are also less likely to receive rotavirus vaccine immunization, the model incorporates a relative coverage correction factor for vaccine efficacy against death. We assumed that vaccine coverage of those most likely to die from rotavirus was $90 \%$ of the vaccine coverage of the remainder of the population. Vaccine efficacy against cases requiring outpatient care was estimated to be the average of the efficacy against severe rotavirus illness $(85 \%)$ and rotavirus illness of any severity (70\%) $[51,72]$. Based on other studies $[4,34,37,44,51,73]$ and confirmed by the Ministry of Health and Sports and the National Rotavirus Surveillance Program, administration costs per dose of vaccine were assumed to be US\$0.50.

\section{Cost-Effectiveness Analysis}

The primary measurement of cost-effectiveness for this study was the incremental costeffectiveness ratio (ICER) per DALY averted. A 3\% discount rate was utilized for all costs and outcomes. The ICER was calculated using a range of vaccine price between US\$3 and US\$24 per dose. Additional outcome variables calculated include the cost per death averted, the break-even price, and estimates of rotavirus-related events and medical costs averted by vaccination. WHO-CHOICE thresholds are used to define a health intervention as very costeffective if the cost per DALY averted is less than the GDP per capita of the nation implementing that intervention [67].

\section{Sensitivity Analysis}

To assess the combined impact of uncertainty in the input parameters, we conducted a Monte Carlo simulation using Crystal Ball version 11.1.2.1.0 (Oracle, CA). Input ranges were defined for each key input parameter based on ranges in published data (Table 1). The Monte Carlo procedure selects one value from each input distribution and is repeated with 10,000 iterations to construct a distribution of likely outputs. A one-way sensitivity analysis with the same input ranges was also conducted to assess the magnitude of impact of each variable on projected cost-effectiveness utilizing the current vaccine price per dose for Bolivia (US\$9.00).

\section{Ethical Considerations}

All portions of the study, including inpatient and outpatient chart abstraction, were approved by Emory University's Institutional Review Board (Protocol IRB00004406) and the Bolivian National Bioethics Committee prior to data collection.

\section{RESULTS}

\section{Study Population and Economic Burden of Rotavirus to Bolivia's Health Care System}

Among hospitalized children in our study population, about $40 \%$ of patients tested positive for rotavirus infection (Table 2). The average length of hospitalization was 4.9 days. The percentage of rotavirus positive cases was not significantly different between cities with sentinel hospitals. On average, children in El Alto had significantly longer hospital stays 
than those in other cities. The mean age for children in our study population was 12.6 months among inpatients and 15 months among outpatients.

In Bolivia, the average total cost for hospitalization was US\$260.57 and the average total cost for an outpatient event was US\$16.88 (Table 3). Generally, the total cost per hospitalization was composed of bed day costs (84\%), medicines (12\%), and diagnostics (4\%). Patients in El Alto incurred significantly higher total bed-day and medication costs, likely due to the significantly longer average length of stay in comparison to other sites. Cochabamba patients had significantly higher diagnostic costs compared to La Paz and Santa Cruz, because it was the only private hospital sampled, and public hospitals run diagnostic tests for diarrhea cases with less frequency. Outpatient costs per patient were similar across all facilities, although Cochabamba had slightly significantly higher outpatient costs compared to other cities.

\section{Estimated Impact of Rotavirus Vaccination on the Economic Burden of Rotavirus to Bolivia's Health Care System}

In the absence of vaccination, we estimated that the birth cohort would experience 47,560 outpatient visits, 9,482 hospitalizations, and 813 deaths before reaching age 5, accounting for 27,753 DALYs (Table 4). As a result of rotavirus related diarrhea, 189 out of every 1,000 children will have received outpatient treatment, 38 out of every 1,000 children will have been hospitalized, and 3 out of every 1,000 children will die by age 5. From these data, we estimated a rotavirus-associated economic burden of US $\$ 3,010,831$ per year from the healthcare perspective (Table 4). In other words, US $\$ 12.00$ in direct medical costs will be spent for every child in the cohort. Though the number of outpatient events was about five times higher than hospitalization events, the majority ( $80 \%$ ) of Bolivia's economic burden was attributable to events requiring hospitalization.

We estimated that universal rotavirus vaccination, with an estimated coverage based on current national DPT coverage, would reduce outpatient and hospitalization visits, deaths, and DALYs by over 60\%. In general, the percentage of events averted increases with vaccination coverage. Notably, we estimated that rotavirus vaccination would reduce annual direct medical costs for rotavirus-associated events by $66 \%$, from US $\$ 3,010,831$ to US $\$ 1,012,027$.

\section{Cost Effectiveness of Rotavirus Vaccination}

International financial subsidies for Bolivia's rotavirus vaccination program do not provide a sustainable strategy for a permanent rotavirus vaccine program. Bolivia has agreed to contribute $40 \%$ of vaccine costs during the first five years of vaccine rollout, eventually moving towards total government financing of the program by 2017 [74]. Given the uncertainty of future vaccination costs, we modeled cost-effectiveness across a plausible range of prices (Table 5). The medical break-even price was calculated at US\$7.62 per vaccine course ( 2 doses). According to WHO standards for cost-effectiveness, an intervention is very cost-effective if the ICER is less than the GDP per capita and cost effective if the ICER is less than three times a nation's GDP per capita. Utilizing Bolivia's GDP (US\$1,758 [75]) as a threshold, rotavirus vaccination is very cost-effective for Bolivia up to a price of US\$67.24 per dose and cost-effective up to a price of US\$194.10 per dose. Using cost per death averted as a measure of cost-effectiveness, rotavirus vaccination would be very cost-effective up to US $\$ 5.66$ per dose and cost-effective up to US $\$ 9.38$ per dose.

\section{Sensitivity and Uncertainty Analysis}

To assess which inputs were the most important drivers of cost-effectiveness at Bolivia's current price per dose (US\$9.00), we varied each individual model input in both one-way 
(Table 6) and probabilistic multivariate sensitivity (Tables 4-5) analyses. None of the input variations for the sensitivity analysis resulted in cost-savings at the current price of US $\$ 9.00$ per dose. In general, ICERs were more affected by variations in the diarrheal mortality (rate of mortality, vaccine efficacy against death) and hospitalization inputs (diarrheal hospitalization rate, hospitalization costs, and vaccine efficacy against hospitalizations) than outpatient inputs (Table 6). Similarly, costs per DALY averted were most sensitive to changes in diarrheal mortality followed by hospitalization inputs, and less sensitive to changes in outpatient inputs (data not shown).

\section{DISCUSSION}

The goal of this report was to estimate the economic burden of rotavirus and costeffectiveness of the rotavirus vaccination program in Bolivia for use in policy development as subsidization of universal rotavirus vaccination is withdrawn in 2017. We estimate the annual economic burden of rotavirus at over US $\$ 3$ million. We found that rotavirus vaccination reduces, by at least $60 \%$, the number of outpatient visits, hospitalizations, deaths, DALY's, and total direct medical costs associated with rotavirus diarrhea. Further, the rotavirus vaccine was cost-savings below a price of US\$3.81 per dose and cost-effective at Bolivia's current price of $\$ 9$ per dose.

The reduction in rotavirus related events and direct medical costs averted are concordant with previously published studies in other lower-middle and upper-middle-income countries $[6,29,36,50,51,76]$. Our estimation of hospitalization costs per patient (Table 3 ) is generally higher than published estimates from countries of similar economic status based on GDP per capita, including Vietnam [4], Indonesia [73], and Kyrgyzstan [37]. Our estimate was most similar to published estimates of hospitalization costs in Peru (\$284.08) [36] and Malaysia (\$187.72) [20], both of which have a higher economic status than Bolivia. As expected, hospitalizations exhibited a larger reduction in events (Table 4) and costs (data not shown) than outpatient visits due to the rotavirus vaccine. This is likely due to greater vaccine efficacy against hospitalizations than against diarrheal episodes requiring outpatient treatment (Table 1) and higher hospitalization costs than outpatient costs (Table 3).

The estimated break-even price was higher than estimates for countries of similar economic status [51,73], and more similar to the break-even price calculated for some upper-middleincome counties including Chile (US\$10.33 per course [51]) and Panama (US\$7.56 per course [51]). The ICERs for rotavirus vaccination in Bolivia (US $\$ 143.84$ per DALY averted at US\$18 per vaccine course) were comparable to ICERs from analyses for countries of similar economic status including Honduras (US\$120.46/DALY averted at US\$14/course) [73] and low-income Asian countries (US\$212/DALY averted at \$20/course) [6].

If Bolivia were to commit the sum of its current government vaccine expenditures (US $\$ 8,294,595$ for 2009 [64]) to universal rotavirus vaccination, it could only afford to purchase the rotavirus vaccine below a price of US\$17.24 per dose (data not shown). Though our model demonstrates cost-effectiveness for even higher prices, this situation is not pragmatic given the numerous essential childhood vaccines that must be considered in the national budget. After the first five years of vaccine rollout subsidized by GAVI, Bolivia will have to allocate a higher percentage of its health systems budget to rotavirus vaccination and renegotiate rotavirus vaccine prices. Based on our analyses, regardless of the final price Bolivia obtains for rotavirus vaccine, universal vaccination will probably remain a highly cost-effective health intervention. It is important to note that rotavirus vaccination in Bolivia, at the current price of $\$ 9 /$ dose, is comparatively more cost-effective than other most other early childhood health interventions such as expansion of oral rehydration therapy or vitamin A supplementation programs (Table 7). It should also be noted that as vaccine 
production expands with accelerated introduction into other countries, the price per dose and cost per DALY averter are likely to decrease and cost-effectiveness ratios will improve [34].

Any results of cost-effectiveness analyses are highly dependent on input data variability [78]. For this reason, sensitivity analyses are crucial to addressing the uncertainty of input parameters. While economic analyses of other developing countries also found costeffectiveness to be most sensitive to mortality and vaccine efficacy inputs $[4,6,41,44,45$, $50,51]$, it is interesting to note that hospitalization rate and costs are typically more important drivers of cost-effectiveness in countries of higher socioeconomic status than Bolivia [6] due to the higher costs associated with hospitalizations in these countries. It is possible that hospitalization inputs were significant drivers of cost-effectiveness in our study because our estimated costs per hospitalization (US\$260.57) were more similar to costs in higher-income countries than Bolivia. However, our base rates of vaccine efficacy are consistent with previous studies using similar methodology $[4,6,29,37,50,51]$ and the 95\% CL for all the outputs include recent real-world effectiveness studies conducted in high-mortality settings [79, 80]. In addition, the range of the estimated percentage of deaths due to diarrhea among under 5 deaths in Bolivia from various sources is 30\%: estimates from WHO and PAHO include 7\% [81], 15\% (used in this model [61]), and 37\% [82]. The variation is exacerbated because we have poor estimates for rotavirus-specific mortality. In this study, we utilize the rotavirus-specific hospitalization rate (40\%) as a proxy for the rotavirus-specific mortality rate; however, of a small sample of children with acute diarrheal disease who died while receiving treatment in Bolivian surveillance hospitals, $70 \%$ were rotavirus positive (communication with Surveillance program staff). Isakbaeva et al. faced an even more difficult challenge in Uzbekistan where there was a $106 \%$ variation in rotavirus diarrhea mortality rates depending on the data source [30]. In summary, the sensitivity analysis does not completely capture the possible variation in reported diarrhea mortality in Bolivia.

The main strength of this study lies in the accuracy and validity of the model inputs. For example, we used values for the proportion of pediatric diarrhea hospitalizations due to rotavirus (gleaned from 4 years of national rotavirus sentinel hospital surveillance across multiple geographic regions), direct medical costs (multi-year data collection from all the sentinel hospitals and WHO-CHOICE data) and vaccine efficacy rates (from Rotarix ${ }^{\text {TM }}$ clinical trials). To achieve robust cost data, we oversampled both inpatient and outpatient study populations. A second strength was our ability to compare cost data collected through vigorous in-country data abstraction to data available from easily accessible data sources such as WHO-CHOICE. We determined that bed-day costs provided by hospital administration departments were not an accurate reflection of true costs, and therefore WHO-CHOICE was a more reliable cost input (Methods). Therefore, we examined a range of possible costs in our sensitivity analysis (Table 1) in order to incorporate what was likely the true hospitalization cost.

Our main limitation was that our analyses did not include data on societal costs borne by families of children with rotavirus. One reason for excluding these costs from this analysis was that these costs are not usually an important driver in economic decision-making by the government. However, studies that have included these data along with health care system costs often estimate a higher level of cost-effectiveness [78]. A second limitation is that our study did not incorporate other variables into the cost-effectiveness estimate such as changing recommended age restrictions for rotavirus vaccine administration [83], possible risk of intussusception in certain populations [83], and possible obstacles to rotavirus vaccine efficacy including: varied host protection with incomplete doses $[84,85]$ and the effect of host nutritional status [86-88]. A third limitation is that our estimations of health care costs and utilization based on the tertiary-level hospitals in the National Rotavirus 
Surveillance Program likely contributed to higher estimations of costs and cost-effectiveness because more severe cases of diarrhea may present at tertiary hospitals than primary or secondary health facilities. In exchange for this limitation, we were able to directly estimate the proportion of laboratory confirmed rotavirus hospitalization and outpatient diarrhea cases and capture a wide range of variation in utilization and costs in Bolivia based on geographic and climatic region and socioeconomic level of the population served.

In conclusion, we found that incorporating rotavirus vaccination in Bolivia's immunization program is a cost-effective intervention to decrease under-five mortality and morbidity and reduce medical expenditures to the health system. Our model demonstrated that universal rotavirus vaccination averted over $60 \%$ of rotavirus related health outcomes and costs and was cost-effective at the current price of $\$ 9$ per dose. However, it is important to practically assess Bolivia's ability to fund universal vaccination as international subsidies are gradually withdrawn over the next five years. Our analyses will help guide Bolivia's decision making process as it considers its future allocations for childhood vaccine programs.

\section{Acknowledgments}

This work was supported in part by The Eugene J. Gangarosa Fund, the Anne E. and William A. Foege Global Health Fund, the O.C. Hubert Charitable Trust, the RSPH Student Initiative Fund, the - NIH Global Frameworks Grant (2007-2010), the Emory University Global Health Institute, the New Aid Fellowship, the Bolivia National Rotavirus Surveillance Program (BNRSP), and the Swedish Cooperation ASDI-UMSA. J.S.L. was supported in part by funds from the Emory University Global Health Institute, NIH-NIAID (1K01AI087724 - 01) and USDANIFA (2010-85212-20608) grants. Thank you also to Ms. Danielle Wagner, Jennifer King, and Sally Embrey who helped in the review of this manuscript and collection of relevant references. Thank you to Mr. Scott Wright for his technical assistance with the analysis. We are grateful for the support of the hospital staff participating in this study.

\section{References}

1. Parashar UD, Gibson CJ, Bresse JS, Glass RI. Rotavirus and severe childhood diarrhea. Emerg Infect Dis. 2006 Feb; 12(2):304-6. [PubMed: 16494759]

2. Parashar UD, Hummelman EG, Bresee JS, Miller MA, Glass RI. Global illness and deaths caused by rotavirus disease in children. Emerg Infect Dis. 2003 May; 9(5):565-72. [PubMed: 12737740]

3. Ehrenkranz P, Lanata CF, Penny ME, Salazar-Lindo E, Glass RI. Rotavirus diarrhea disease burden in Peru: the need for a rotavirus vaccine and its potential cost savings. Rev Panam Salud Publica. 2001 Oct; 10(4):240-8. [PubMed: 11715170]

4. Fischer TK, Anh DD, Antil L, Cat ND, Kilgore PE, Thiem VD, et al. Health care costs of diarrheal disease and estimates of the cost-effectiveness of rotavirus vaccination in Vietnam. J Infect Dis. 2005 Nov 15; 192(10):1720-6. [PubMed: 16235169]

5. O’Ryan M, Perez-Schael I, Mamani N, Pena A, Salinas B, Gonzalez G, et al. Rotavirus-associated medical visits and hospitalizations in South America: a prospective study at three large sentinel hospitals. Pediatr Infect Dis J. 2001 Jul; 20(7):685-93. [PubMed: 11465841]

6. Podewils LJ, Antil L, Hummelman E, Bresee J, Parashar UD, Rheingans R. Projected costeffectiveness of rotavirus vaccination for children in Asia. J Infect Dis. 2005 Sep 1; 192( Suppl 1):S133-45. [PubMed: 16088797]

7. Rheingans RD, Constenla D, Antil L, Innis BL, Breuer T. Economic and health burden of rotavirus gastroenteritis for the 2003 birth cohort in eight Latin American and Caribbean countries. Rev Panam Salud Publica. 2007 Apr; 21(4):192-204. [PubMed: 17612463]

8. Rheingans RD, Heylen J, Giaquinto C. Economics of rotavirus gastroenteritis and vaccination in Europe: what makes sense? Pediatr Infect Dis J. 2006 Jan; 25(1 Suppl):S48-55. [PubMed: 16397429]

9. Al Awaidy SA, Bawikar S, Al Busaidy S, Baqiani S, Al Abedani I, Varghese R, et al. Considerations for introduction of a rotavirus vaccine in Oman: rotavirus disease and economic burden. J Infect Dis. 2009 Nov 1; 200( Suppl 1):S248-53. [PubMed: 19817605] 
10. Nelson EA, Tam JS, Yu LM, Ng YC, Bresee JS, Poon KH, et al. Hospital-based study of the economic burden associated with rotavirus diarrhea in Hong Kong. J Infect Dis. 2005 Sep 1; 192( Suppl 1):S64-70. [PubMed: 16088808]

11. Muhsen K, Shulman L, Rubinstein U, Kasem E, Kremer A, Goren S, et al. Incidence, characteristics, and economic burden of rotavirus gastroenteritis associated with hospitalization of israeli children <5 years of age, 2007-2008. J Infect Dis. 2009 Nov 1; 200( Suppl 1):S254-63. [PubMed: 19817606]

12. Lee BP, Azimi PH, Staat MA, Louie L, Parada E, Berke T, et al. Nonmedical costs associated with rotavirus disease requiring hospitalization. Pediatr Infect Dis J. 2005 Nov; 24(11):984-8. [PubMed: 16282934]

13. Tucker AW, Haddix AC, Bresee JS, Holman RC, Parashar UD, Glass RI. Cost-effectiveness analysis of a rotavirus immunization program for the United States. JAMA. 1998 May 6; 279(17): 1371-6. [PubMed: 9582045]

14. Mendelsohn AS, Asirvatham JR, Mkaya Mwamburi D, Sowmynarayanan TV, Malik V, Muliyil J, et al. Estimates of the economic burden of rotavirus-associated and all-cause diarrhoea in Vellore, India. Trop Med Int Health. 2008 Jul; 13(7):934-42. [PubMed: 18466182]

15. Standaert B, Harlin O, Desselberger U. The financial burden of rotavirus disease in four countries of the European Union. Pediatr Infect Dis J. 2008; 27(1):S20.

16. Nakagomi T, Nakagomi O, Takahashi Y, Enoki M, Suzuki T, Kilgore PE. Incidence and burden of rotavirus gastroenteritis in Japan, as estimated from a prospective sentinel hospital study. J Infect Dis. 2005 Sep 1; 192( Suppl 1):S106-10. [PubMed: 16088792]

17. Martinon-Torres F, Bouzon-Alejandro M, Lopez-Sousa M, Redondo-Collazo L, Almeida-Agudin $\mathrm{S}$, Astorgano-Fernandez C, et al. An estimation of indirect costs caused by acute rotavirus gastroenteritis in a Galician area, Spain. Eur J Pediatr. 2008 Mar; 167(3):337-9. [PubMed: 17364172]

18. Lu CY, Lauderdale TL, Fang YH, Wang CY, Ho YH, Hung CL, et al. Disease burden and related medical costs of rotavirus infections in Taiwan. BMC Infect Dis. 2006; 6:176. [PubMed: 17173677]

19. Lorgelly PK, Joshi D, Iturriza Gomara M, Flood C, Hughes CA, Dalrymple J, et al. Infantile gastroenteritis in the community: a cost-of-illness study. Epidemiol Infect. 2008 Jan; 136(1):3443. [PubMed: 17338837]

20. Lee WS, Poo MI, Nagaraj S. Estimates of economic burden of providing inpatient care in childhood rotavirus gastroenteritis from Malaysia. J Paediatr Child Health. 2007 Dec; 43(12):81825. [PubMed: 17608648]

21. Huet F, Largeron N, Trichard M, Miadi-Fargier H, Jasso-Mosqueda G. Burden of paediatric rotavirus gastroenteritis and potential benefits of a universal rotavirus vaccination programme with RotaTeq in France. Vaccine. 2007 Aug 21; 25(34):6348-58. [PubMed: 17629598]

22. Harris JP, Jit M, Cooper D, Edmunds WJ. Evaluating rotavirus vaccination in England and Wales. Part I. Estimating the burden of disease. Vaccine. 2007 May 16; 25(20):3962-70. [PubMed: 17395343]

23. Gil A, Carrasco P, Jimenez R, San-Martin M, Oyaguez I, Gonzalez A. Burden of hospitalizations attributable to rotavirus infection in children in Spain, period 1999-2000. Vaccine. 2004 Jun 2; 22(17-18):2221-5. [PubMed: 15149780]

24. Giaquinto C, Van Damme P, Huet F, Gothefors L, Van der Wielen M. Costs of communityacquired pediatric rotavirus gastroenteritis in 7 European countries: the REVEAL Study. J Infect Dis. 2007 May 1; 195( Suppl 1):S36-S44. [PubMed: 17539193]

25. Chen KT, Fan SF, Tang RB, Huang YF, Lee PI, Chen PY, et al. Hospital-based study of the economic burden associated with rotavirus diarrhea in Taiwan. Vaccine. 2007 May 22; 25(21): 4266-72. [PubMed: 17360079]

26. Chan PK, Tam JS, Nelson EA, Fung KS, Adeyemi-Doro FA, Fok TF, et al. Rotavirus infection in Hong Kong: epidemiology and estimates of disease burden. Epidemiol Infect. 1998 Jun; 120(3): 321-5. [PubMed: 9692611] 
27. Bilcke J, Van Damme P, De Smet F, Hanquet G, Van Ranst M, Beutels P. The health and economic burden of rotavirus disease in Belgium. Eur J Pediatr. 2008 Dec; 167(12):1409-19. [PubMed: 18317802]

28. Fruhwirth M, Berger K, Ehlken B, Moll-Schuler I, Brosl S, Mutz I. Economic impact of community- and nosocomially acquired rotavirus gastroenteritis in Austria. Pediatr Infect Dis J. 2001 Feb; 20(2):184-8. [PubMed: 11224839]

29. Constenla D, O'Ryan M, Navarrete MS, Antil L, Rheingans RD. Potential cost effectiveness of a rotavirus vaccine in Chile. Rev Med Chil. 2006 Jun; 134(6):679-88. [PubMed: 17130941]

30. Isakbaeva ET, Musabaev E, Antil L, Rheingans R, Juraev R, Glass RI, et al. Rotavirus disease in Uzbekistan: cost-effectiveness of a new vaccine. Vaccine. 2007 Jan 4; 25(2):373-80. [PubMed: 16930784]

31. Newall AT, Beutels P, Macartney K, Wood J, MacIntyre CR. The cost-effectiveness of rotavirus vaccination in Australia. Vaccine. 2007 Dec 17; 25(52):8851-60. [PubMed: 18022735]

32. Smith JC, Haddix AC, Teutsch SM, Glass RI. Cost-effectiveness analysis of a rotavirus immunization program for the United States. Pediatrics. 1995 Oct; 96(4 Pt 1):609-15. [PubMed: 7567319]

33. Ho AM, Nelson EA, Walker DG. Rotavirus vaccination for Hong Kong children: an economic evaluation from the Hong Kong Government perspective. Arch Dis Child. 2008 Jan; 93(1):52-8. [PubMed: 17855438]

34. Atherly D, Dreibelbis R, Parashar UD, Levin C, Wecker J, Rheingans RD. Rotavirus vaccination: cost-effectiveness and impact on child mortality in developing countries. J Infect Dis. 2009 Nov 1; 200( Suppl 1):S28-38. [PubMed: 19817610]

35. Carlin JB, Jackson T, Lane L, Bishop RF, Barnes GL. Cost effectiveness of rotavirus vaccination in Australia. Aust N Z J Public Health. 1999 Dec; 23(6):611-6. [PubMed: 10641352]

36. Clark AD, Walker DG, Mosqueira NR, Penny ME, Lanata CF, Fox-Rushby J, et al. Costeffectiveness of rotavirus vaccination in Peru. J Infect Dis. 2009 Nov 1; 200( Suppl 1):S114-24. [PubMed: 19817591]

37. Flem ET, Latipov R, Nurmatov ZS, Xue Y, Kasymbekova KT, Rheingans RD. Costs of diarrheal disease and the cost-effectiveness of a rotavirus vaccination program in kyrgyzstan. J Infect Dis. 2009 Nov 1; 200( Suppl 1):S195-202. [PubMed: 19817600]

38. Giammanco MD, Coniglio MA, Pignato S, Giammanco G. An economic analysis of rotavirus vaccination in Italy. Vaccine. 2009 Jun 12; 27(29):3904-11. [PubMed: 19446934]

39. Goossens LM, Standaert B, Hartwig N, Hovels AM, Al MJ. The cost-utility of rotavirus vaccination with Rotarix (RIX4414) in the Netherlands. Vaccine. 2008 Feb 20; 26(8):1118-27. [PubMed: 18215445]

40. Griffiths RI, Anderson GF, Powe NR, Oliveras E, Herbert RJ, Grant CC, et al. Economic impact of immunization against rotavirus gastroenteritis. Evidence from a clinical trial. Arch Pediatr Adolesc Med. 1995 Apr; 149(4):407-14. [PubMed: 7704169]

41. Kim SY, Goldie SJ, Salomon JA. Cost-effectiveness of Rotavirus vaccination in Vietnam. BMC Public Health. 2009; 9:29. [PubMed: 19159483]

42. Martin A, Batty A, Roberts JA, Standaert B. Cost-effectiveness of infant vaccination with RIX4414 (Rotarix) in the UK. Vaccine. 2009 Jul 16; 27(33):4520-8. [PubMed: 19446594]

43. Panatto D, Amicizia D, Ansaldi F, Marocco A, Marchetti F, Bamfi F, et al. Burden of rotavirus disease and cost-effectiveness of universal vaccination in the Province of Genoa (Northern Italy). Vaccine. 2009 May 26; 27(25-26):3450-3. [PubMed: 19200850]

44. Rheingans RD, Antil L, Dreibelbis R, Podewils LJ, Bresee JS, Parashar UD. Economic costs of rotavirus gastroenteritis and cost-effectiveness of vaccination in developing countries. J Infect Dis. 2009 Nov 1; 200( Suppl 1):S16-27. [PubMed: 19817595]

45. de Soarez PC, Valentim J, Sartori AM, Novaes HM. Cost-effectiveness analysis of routine rotavirus vaccination in Brazil. Rev Panam Salud Publica. 2008 Apr; 23(4):221-30. [PubMed: 18505602]

46. Tate JE, Rheingans RD, O'Reilly CE, Obonyo B, Burton DC, Tornheim JA, et al. Rotavirus disease burden and impact and cost-effectiveness of a rotavirus vaccination program in kenya. $\mathrm{J}$ Infect Dis. 2009 Nov 1; 200( Suppl 1):S76-84. [PubMed: 19817618] 
47. Wang XY, Riewpaiboon A, von Seidlein L, Chen XB, Kilgore PE, Ma JC, et al. Potential costeffectiveness of a rotavirus immunization program in rural China. Clin Infect Dis. 2009 Oct 15; 49(8):1202-10. [PubMed: 19739973]

48. Widdowson MA, Meltzer MI, Zhang X, Bresee JS, Parashar UD, Glass RI. Cost-effectiveness and potential impact of rotavirus vaccination in the United States. Pediatrics. 2007 Apr; 119(4):68497. [PubMed: 17403839]

49. Chodick G, Waisbourd-Zinman O, Shalev V, Kokia E, Rabinovich M, Ashkenazi S. Potential impact and cost-effectiveness analysis of rotavirus vaccination of children in Israel. Eur J Public Health. 2009 Jun; 19(3):254-9. [PubMed: 19221026]

50. Constenla D, Velazquez FR, Rheingans RD, Antil L, Cervantes Y. Economic impact of a rotavirus vaccination program in Mexico. Rev Panam Salud Publica. 2009 Jun; 25(6):481-90. [PubMed: 19695142]

51. Rheingans RD, Constenla D, Antil L, Innis BL, Breuer T. Potential cost-effectiveness of vaccination for rotavirus gastroenteritis in eight Latin American and Caribbean countries. Rev Panam Salud Publica. 2007 Apr; 21(4):205-16. [PubMed: 17612464]

52. Miller MA, McCann L. Policy analysis of the use of hepatitis B, Haemophilus influenzae type b-, Streptococcus pneumoniae-conjugate and rotavirus vaccines in national immunization schedules. Health Econ. 2000 Jan; 9(1):19-35. [PubMed: 10694757]

53. Bilcke J, Van Damme P, Beutels P. Cost-effectiveness of rotavirus vaccination: exploring caregiver(s) and "no medical care" disease impact in Belgium. Med Decis Making. 2009 Jan-Feb; 29(1):33-50. [PubMed: 18948433]

54. Jit M, Edmunds WJ. Evaluating rotavirus vaccination in England and Wales. Part II. The potential cost-effectiveness of vaccination. Vaccine. 2007 May 16; 25(20):3971-9. [PubMed: 17400341]

55. Lorgelly PK, Joshi D, Iturriza Gomara M, Gray J, Mugford M. Exploring the cost effectiveness of an immunization programme for rotavirus gastroenteritis in the United Kingdom. Epidemiol Infect. 2008 Jan; 136(1):44-55. [PubMed: 17335631]

56. Melliez H, Levybruhl D, Boelle PY, Dervaux B, Baron S, Yazdanpanah Y. Cost and costeffectiveness of childhood vaccination against rotavirus in France. Vaccine. 2008 Jan 30; 26(5): 706-15. [PubMed: 18166250]

57. Wu CL, Yang YC, Huang LM, Chen KT. Cost-effectiveness of childhood rotavirus vaccination in Taiwan. Vaccine. 2009 Mar 4; 27(10):1492-9. [PubMed: 19186200]

58. Zomer TP, van Duynhoven YT, Mangen MJ, van der Maas NA, Vennema H, Boot H, et al. Assessing the introduction of universal rotavirus vaccination in the Netherlands. Vaccine. $2008 \mathrm{Jul}$ 4; 26(29-30):3757-64. [PubMed: 18514975]

59. Takala AK, Koskenniemi E, Joensuu J, Makela M, Vesikari T. Economic evaluation of rotavirus vaccinations in Finland: randomized, double-blind, placebo-controlled trial of tetravalent rhesus rotavirus vaccine. Clin Infect Dis. 1998 Aug; 27(2):272-82. [PubMed: 9709876]

60. UNICEF. Bolivia: Situation of poverty in the country. [cited 2008 February 21]; Available from: http://www.unicef.org/bolivia/resources_2332.htm

61. World Health Organization. Mortality Country Fact Sheet 2006 - Bolivia. Geneva: World Health Organization; 2006. p. 2

62. World Health Organization. Health Profile - Bolivia (Plurinational State of). [Webpage]. 2011 August 13. 2010 [cited 2011 April 2011]; Available from: http://www.who.int/gho/countries/bol.pdf

63. Intituto Nacional de Estadistica. Bolivia: 2008.

64. World Health Organization. Immunization Profile - Bolivia (Plurinational State of). [Webpage]. 2010 June 1. 2010 [cited 2010 June 1]; Available from: http://apps.who.int/immunization_monitoring/en/globalsummary/countryprofileresult.cfm?C='bol'

65. Ministerio de Salud y Deportes. Sistema Naconal de Información en Salud y Vigilancia Epidemiologica (SNIS). Ministerio de Salud y Deportes; 2011.

66. Griffiths, U.; Rheingans, R.; Walker, D. Guidelines for estimating the economic burden of diarrhoeal disease with focus on assessing the costs of rotavirus diarrhoea. Geneva: World Health Organization; 2004.

67. World Health Organization. WHO-CHOICE: CHOosing Interventions that are Cost-Effective. 
68. World Health Organization. Unit Costs for Patient Services-WHO-CHOICE. Geneva: WHOCHOICE;

69. McFadyen, JE. International Drug Price Indicator Guide. 2007.

70. International Dispensary Association Foundation. International Dispensary Association's Web Catalogue. 2009. 2009.

71. Demographic and Health Surveys. Bolivia: Standard DHS, 2003. 2003. Measure DHS; 2003.

72. Ruiz-Palacios GM, Perez-Schael I, Velazquez FR, Abate H, Breuer T, Clemens SC, et al. Safety and efficacy of an attenuated vaccine against severe rotavirus gastroenteritis. N Engl J Med. 2006 Jan 5; 354(1):11-22. [PubMed: 16394298]

73. Wilopo SA, Kilgore P, Kosen S, Soenarto Y, Aminah S, Cahyono A, et al. Economic evaluation of a routine rotavirus vaccination programme in Indonesia. Vaccine. 2009 Nov 20; 27( Suppl 5):F6774. [PubMed: 19931723]

74. Global Alliance Vaccine Initiative. GAVI: Application Form for Country Proposals for support to new and under-used vaccines. Bolivia: 2008.

75. The World Bank. GDP per capita (current US\$) 2009 [cited 2011 April 28]; Webpage]. Available from: http://data.worldbank.org/indicator/NY.GDP.PCAP.CD

76. World Bank. Country and Lending Groups. [Webpage]. 2010. [cited 2010 June 1]; Available from: http://data.worldbank.org/about/country-classifications/country-and-lending-groups

77. Ortega O, El-Sayed N, Sanders JW, Abd-Rabou Z, Antil L, Bresee J, et al. Cost-benefit analysis of a rotavirus immunization program in the Arab Republic of Egypt. J Infect Dis. 2009 Nov 1; 200( Suppl 1):S92-8. [PubMed: 19817621]

78. Bilcke J, Beutels P. Reviewing the cost effectiveness of rotavirus vaccination: the importance of uncertainty in the choice of data sources. Pharmacoeconomics. 2009; 27(4):281-97. [PubMed: 19485425]

79. Linhares AC, Velazquez FR, Perez-Schael I, Saez-Llorens X, Abate H, Espinoza F, et al. Efficacy and safety of an oral live attenuated human rotavirus vaccine against rotavirus gastroenteritis during the first 2 years of life in Latin American infants: a randomised, double-blind, placebocontrolled phase III study. Lancet. 2008 Apr 5; 371(9619):1181-9. [PubMed: 18395579]

80. Jiang V, Jiang B, Tate J, Parashar UD, Patel MM. Performance of rotavirus vaccines in developed and developing countries. Hum Vaccin. 2010 Jul 21.6:7.

81. Pan American Health Organization. Health Situation in the Americas: Basic Indicators 2007. Washington D.C: Pan American Health Organization; 2007. p. 12

82. Pan American Health Organization. Health situation analysis and trends summary-Bolivia. 2005. [cited 2010 June 1]; Available from: http://www.paho.org/english/DD/AIS/cp_068.htm

83. Global Advisory Committee on Vaccine Safety. Statement on Rotarix and Rotateq vaccines and intussusception. 2011. [cited 2011 April 2011]; Available from: http://www.who.int/vaccine_safety/topics/rotavirus/rotarix_and_rotateq/intussusception_sep2010/ en/index.html

84. Dennehy PH, Vesikari T, Matson DO, Itzler RF, Dallas MJ, Goveia M, et al. Efficacy of the pentavalent rotavirus vaccine, RotaTeq(R) (RV5), between doses of a 3-dose series and with less than 3 doses (incomplete regimen). Hum Vaccin. 2011 May 1.7(5)

85. de Blasio BF, Kasymbekova K, Flem E. Dynamic model of rotavirus transmission and the impact of rotavirus vaccination in Kyrgyzstan. Vaccine. 2010 Nov 23; 28(50):7923-32. [PubMed: 20933563]

86. Moore SE, Goldblatt D, Bates CJ, Prentice AM. Impact of nutritional status on antibody responses to different vaccines in undernourished Gambian children. Acta Paediatr. 2003; 92(2):170-6. [PubMed: 12710642]

87. Waibale P, Bowlin SJ, Mortimer EA Jr, Whalen C. The effect of human immunodeficiency virus-1 infection and stunting on measles immunoglobulin-G levels in children vaccinated against measles in Uganda. Int J Epidemiol. 1999 Apr; 28(2):341-6. [PubMed: 10342701]

88. Powell GM. Response to live attenuated measles vaccine in children with severe kwashiorkor. Ann Trop Paediatr. 1982 Sep; 2(3):143-5. [PubMed: 6191631] 
Table 1

Variables used in the cost-effectiveness and impact analyses

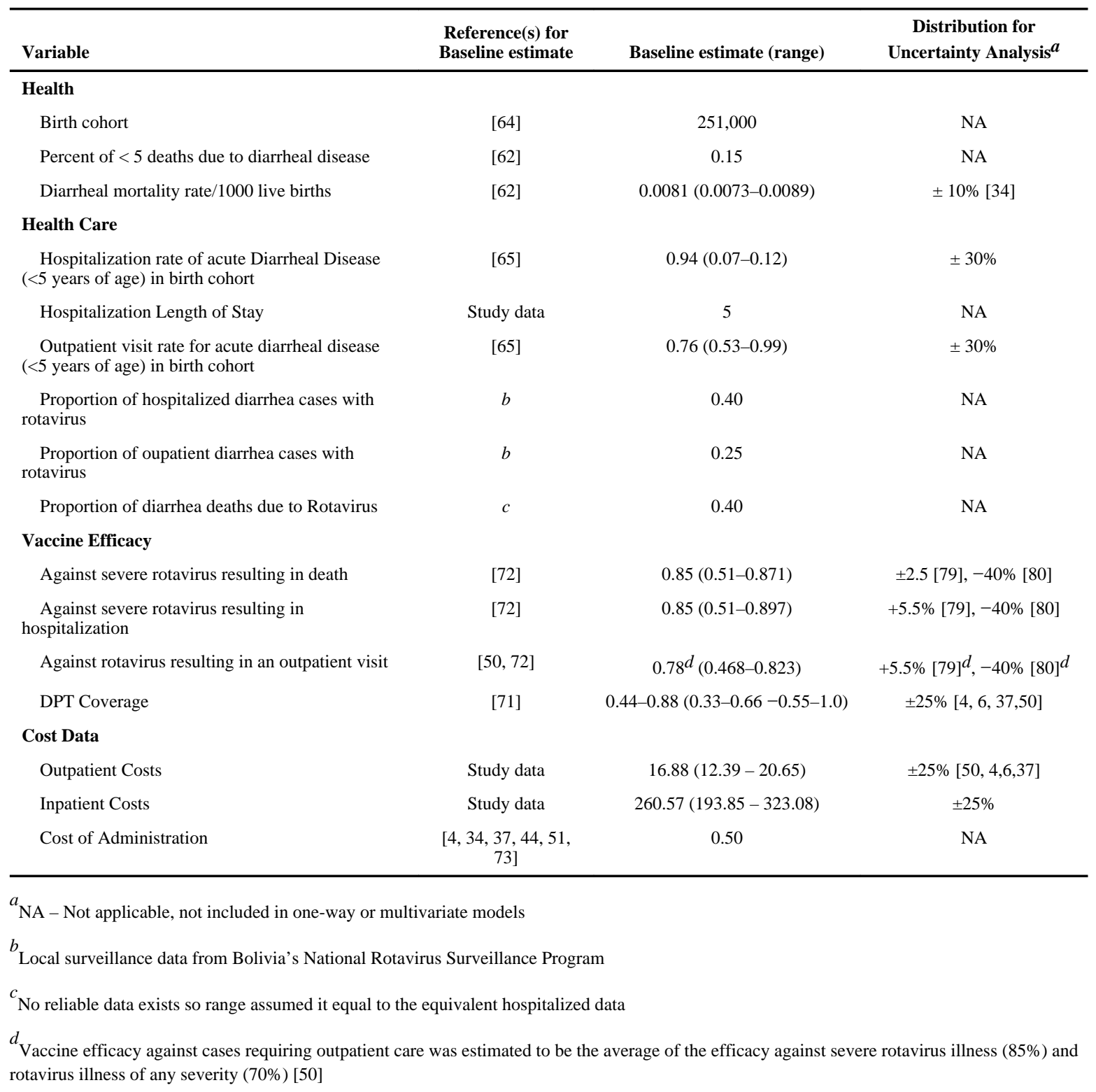

Vaccine. Author manuscript; available in PMC 2012 September 2. 
Table 6

Sensitivity Analysis (At US $\$ 9.00 / \operatorname{dose}^{a}$ )

\begin{tabular}{|c|c|c|c|c|}
\hline Variable & Input Value & $\%$ Change $^{b}$ & $\operatorname{ICER}^{c}$ & \% Change \\
\hline \multicolumn{5}{|c|}{ Diarrheal mortality rate } \\
\hline & 0.010 & +20 & 119.92 & -17 \\
\hline & 0.008 & Baseline & 143.84 & 0 \\
\hline & 0.006 & -20 & 179.68 & +25 \\
\hline \multicolumn{5}{|c|}{ Diarrheal hospitalization rate } \\
\hline & 0.12 & +30 & 114.86 & -20.1 \\
\hline & 0.0945 & Baseline & 143.84 & 0 \\
\hline & 0.07 & -30 & 172.82 & +20.1 \\
\hline \multicolumn{5}{|c|}{ Diarrheal outpatient rate } \\
\hline & 0.99 & +30 & 137.36 & -4.5 \\
\hline & 0.7581 & Baseline & 143.84 & 0 \\
\hline & 0.53 & -30 & 150.32 & +4.5 \\
\hline \multicolumn{5}{|c|}{ Hospitalization Costs ${ }^{a}$} \\
\hline & 325.71 & +25 & 119.69 & -17 \\
\hline & 260.57 & Baseline & 143.84 & 0 \\
\hline & 195.43 & -25 & 167.99 & +17 \\
\hline \multicolumn{5}{|c|}{ Outpatient Costs ${ }^{a}$} \\
\hline & 21.10 & +25 & 138.45 & -4 \\
\hline & 16.88 & Baseline & 143.84 & 0 \\
\hline & 12.66 & -25 & 149.24 & +4 \\
\hline \multicolumn{5}{|c|}{ Vaccine Efficacy Against Death } \\
\hline & 0.871 & +2.5 & 140.34 & -2.4 \\
\hline & 0.85 & Baseline & 143.84 & 0 \\
\hline & 0.51 & -40 & 239.31 & +66.4 \\
\hline \multicolumn{5}{|c|}{ Vaccine Efficacy Against Hospitalizations } \\
\hline & 0.897 & +5.5 & 138.53 & -3.7 \\
\hline & 0.85 & Baseline & 143.84 & 0 \\
\hline & 0.51 & -40 & 182.49 & +26.9 \\
\hline \multicolumn{5}{|c|}{ Vaccine Efficacy Against Outpatient Visits } \\
\hline & 0.823 & +5.5 & 142.65 & -0.8 \\
\hline & 0.780 & Baseline & 143.84 & 0 \\
\hline & 0.468 & -40 & 152.50 & +6 \\
\hline
\end{tabular}

Vaccine. Author manuscript; available in PMC 2012 September 2. 


\section{Table 7}

Comparison of cost-effectiveness ratios of various childhood health interventions to prevent diarrhea mortality for high-mortality nations in the WHO Americas region.

\begin{tabular}{|c|c|c|}
\hline Intervention & $\operatorname{ICER}^{a}$ & Source \\
\hline \multicolumn{3}{|c|}{ Rotavirus vaccination in Bolivia } \\
\hline At $\$ 3 /$ dose & CS & This study \\
\hline At $\$ 4 /$ dose & $\$ 5.27$ & This study \\
\hline At $\$ 5 /$ dose & $\$ 32.98$ & This study \\
\hline At $\$ 9 /$ dose & $\$ 143.84$ & This study \\
\hline At $\$ 10 /$ dose & $\$ 171.56$ & This study \\
\hline $\begin{array}{l}\text { Oral rehydration therapy } \\
\text { Expansion to } 80 \%\end{array}$ & $\$ 249.00$ & {$[67]$} \\
\hline $\begin{array}{l}\text { Oral rehydration therapy } \\
\text { Expansion to } 95 \%\end{array}$ & $\$ 289.00$ & {$[67]$} \\
\hline $\begin{array}{l}\text { Vitamin A supplementation } \\
\text { Expansion to } 50 \%\end{array}$ & $\$ 209.00$ & {$[67]$} \\
\hline $\begin{array}{l}\text { Vitamin A supplementation } \\
\text { Expansion to } 80 \%\end{array}$ & $\$ 393.00$ & {$[67]$} \\
\hline $\begin{array}{l}\text { Zinc supplementation } \\
\text { Expansion to } 50 \%\end{array}$ & $\$ 43.00$ & {$[67]$} \\
\hline $\begin{array}{l}\text { Zinc supplementation } \\
\text { Expansion to } 80 \%\end{array}$ & $\$ 40.00$ & [67] \\
\hline
\end{tabular}

${ }^{a}$ Cost-Effectiveness Ratio defined as cost per DALY averted (US\$/DALY). 95\% CL were estimated from a multivariate sensitivity model described in Methods. CS - Cost Savings. 